\title{
Political Participation: A Matter of Community, Stress, Job Autonomy, and Contact by Political Organizations
}

\author{
Shawn M. Burn and Alison M. Konrad
}

This research is an integration of previous work on political activity and examines a variety of factors thought to be influential in the performance and nonperformance of political behavior. The political participation of a randomly selected sample of local citizens was studied using survey research methods. One hundred and twenty-six individuals responded to survey items assessing participation in a variety of political activities including voting, campaigning, demonstrating, and contacting government officials. Stress, job autonomy, locus of control, contact by political organizations, membership in social groups, income, education, and age were used as independent variables. Regression analyses indicated that stress, job autonomy, number of social organizations belonged to, contact by political organizations, and income accounted for a significant portion of the variance in political activity.

\section{INTRODUCTION}

Policy-makers tend to respond best to the interests of those who contact them, work on or contribute money to their campaigns, and vote for them. Thus, the interests of lower-income groups and other nonparticipators may be underrepresented in the process of public policy formation. Some writers have argued that limited participation and apathy contribute to political stability since most individuals are not competent to vote on most matters anyway. It is beyond the scope of the present paper to substantively argue this issue. However, it is the authors' contention that the changes necessary to increase participation without coercion, such as increased access to quality education, increased job autonomy, and reduced stress, would also make for individuals more capable of informed participation in addition to increasing their quality of life.

Political participation is often related by researchers to demographic factors such as socioeconomic status, which, while descriptive, explain little about why individuals do and do not participate politically. Some researchers have attempted to develop explanations for this relationship (e.g., Zipp et al., 1982). The present study is an integration of previous work and examines a variety of explanations for differences in levels of political participation.

\section{STRESS AND POLITICAL PARTICIPATION}

One concept which may aid in the development of an explanation for varying levels of political participation is stress. Milgram's (1970) concept of overload, developed to explain the effects of population density on everyday life, may be helpful in explaining low levels of political activity. Overload refers to a system's (in this case, the individual's) inability to process inputs from the environment because (a) there are too many inputs or (b) inputs come too fast. When overload is present, the individual adapts by selectively attending to inputs and even ignoring some inputs altogether. In the highly stressful environment of postindustrial society, political participation may decrease as other, more immediate, demands for the individual's time and resources increase. However, some stressors could conceivably lead to greater political participation if political action is perceived as a way to reduce them.

A number of research findings suggest that political participation does decline when other demands on the individual increase. For example, in a study of a national representative sample of U.S. citizens, McGlen (1980) found that having young children decreased women's political participation. Lafferty (1980) reported a similar finding in a study of a national representative sample of Norwegian citizens. 
Another stressful factor, preoccupation with personal problems, has also been found to lead to a decline in political participation in large, representative studies (Dawson et al., 1977).

Research also indicates that as the amount of time and energy needed for participation increases, the likelihood that an individual will participate decreases. For example, researchers have found that individuals who move to a new community and must reregister to vote are less likely than others to vote (Erikson, 1981; King, 1981; Sanders, 1980).

Many researchers have noted that there is a positive relationship between socioeconomic status (SES) and political activity (Acock and Scott, 1980; Orbell, 1974; Powell and Brown, 1981; Sanders, 1980; Wolfinger et al., 1981; Zipp et al., 1982). One possible explanation for this is that lower SES persons may suffer from greater stress in general than do higher SES persons. Low-income individuals are more likely than high-income individuals to experience unemployment, crowded or poor living conditions, and financial worry. Therefore, it seems likely that life-stress may partially explain the relationship between SES and political participation.

\section{FEELINGS OF CONTROL AND PARTICIPATION: JOB AUTONOMY AND LOCUS OF CONTROL}

Stress researchers emphasize the role of personal control in the perception and experience of stress, arguing that the negative psychological effects of stress can be reduced when individuals feel they have personal control over the stressors (Glass et al., 1971; Sherrod et al., 1977). Individuals who feel they have control over their lives may be affected less negatively by stressors than individuals with feelings of little control.

A related issue deals with the effects of personal control on political participation. Early political theorists such as Jean-Jacques Rousseau and John Stuart Mill, as well as the British author Carol Pateman (1970) have argued that participatory experiences and control at the workplace increase the ability and desire to participate politically. Not only may these experiences educate people and prepare them for participation, but experiences of control may also reduce the effects of stressors which, as suggested above, may interfere with political activity. One study (Jackson, 1983) found that participation at work reduced job-related strain. Increased job autonomy may indirectly increase political participation by reducing stress as well as directly educating workers in participatory behaviors.

Job autonomy refers to the amount of control individuals have over their work, including how fast they work, the order in which they perform tasks, and input in decisions which affect their work. Locus of control refers to whether individuals feel they can or cannot control external events (Rot-ter, 1973). People who feel they can influence the world around them are said to possess internal locus of control. Internal locus of control has been found to be positively related to political activity in several empirical studies (Abramowitz, 1973; Dawson et al., 1977; Fendrich and Tarleau, 1973; Reimanis, 1982; Scaturo and Smalley, 1980; Stone, 1974). However, one researcher, Abramowitz (1973), indicated that this relationship held only for those scale items which assess feelings of control over political and world events.

There is also empirical evidence for the notion that participatory experiences in all areas of life lead to increased political participation. Almond and Verba (1963) found that participatory experiences in the family, school, and job were all positively related to political participation among a national representative sample. Gardell (1977) and Elden (1981) found that workers were more likely to desire participation in representative democratic processes if they had high levels of discretion in managing their own work.

It is possible that the low job autonomy experienced by lower-income workers may partially explain the positive SES-political activity relationship. There is also some evidence (Quinn and Shepard, 1974) 
that workers in low-paying, low-skill jobs have considerably less autonomy on the job than do workers in managerial or skilled jobs.

\section{CONTACT BY POLITICAL ORGANIZATIONS AND POLITICAL PARTICIPATION}

Contact by political organizations has been found to increase the political participation of individuals (Zipp et a/., 1982). Since such contact may provide the specific information that makes it easier to participate and may let individuals know that their participation is noticed and valued, it is not surprising that contact may increase the political activity of individuals. Zipp et a/. (1982) also found that individuals with high incomes were more likely to be contacted by political organizations than were those with low incomes. However, their analyses indicated that the effects of SES on participation persisted even when party contact was held constant.

\section{MEMBERSHIP IN SOCIAL GROUPS AND POLITICAL PARTICIPATION}

Membership in social groups may increase political participation by giving individuals a feeling that they belong to a larger community as well as by providing experiences in affecting group outcomes. A number of researchers have found that individuals who belong to social groups show relatively high levels of political participation (Almond and Verba, 1965; Miller, 1982; Sallach et al., 1972; Verba and Nie, 1972).

\section{SURVEY METHODOLOGY}

The present study consisted of a mail survey designed to determine the amount of variance in political participation accounted for by the following: stress and worry, contact with political and social organizations, job autonomy, locus of control and demographic variables.

\section{Subjects}

In Fall 1984, a mail survey was sent to three hundred randomly selected residents of Ontario and Upland, California. These two neighboring cities lie in Southern California in what is known as the Pomona Valley. The median family income in Upland is \$25,582; in Ontario, \$20,759; in the state of California, \$21,537; and in the United States, \$19,917 (as indicated by 1980 Census data).

A mailed format for the questionnaire was chosen as an economical method of data collection, and telephone pretesting indicated that some of the more complex items (such as locus of control and stress) were difficult to communicate over the phone. Two mailings, both including a copy of the survey and a self-addressed stamped envelope, were sent to the sampled participants. Commemorative stamps were used on all correspondence, since this has been found to increase response rate (Dillman, 1978; Linsky, 1975). Similarly, because research has shown that monetary incentives are effective in increasing response rates to mail surveys (Armstrong, 1975; Gunn and Rhodes, 1981; Linsky, 1975), participants were offered a chance to participate in a random drawing for a $\$ 25.00$ prize.

Since the dependent variable of political participation included an item asking whether or not a respondent was registered to vote, the voter registration record was deemed inappropriate as a sampling frame. As no other city directory was available, the telephone directory was used as a sampling frame. Previous researchers have determined that telephone directories can be successfully used to obtain representative samples of the population (Kviz, 1984). Households were selected randomly. Page numbers were randomly selected with replacement and then individual households were randomly selected from the page. Questionnaires were addressed to the household member whose name appeared in the telephone listing. The cover letter indicated that the questionnaire could be completed by any 
adult member (18 years or older) of the household. Unfortunately, this procedure did result in a greater proportion of male respondents than exists in the true population as determined from Census data (20\% more).

Of the 300 surveys sent, 20 were returned due to insufficient addresses, one was returned because the subject was too old and infirm to respond, and one was returned because the subject was deceased. Responses were received from 126 of the remaining 278 surveys, a $45 \%$ rate. This sample was then compared to Census data to determine how representative it was of the Ontario and Upland population. The comparison indicated that the proportion of older respondents was slightly higher in the sample than in the population and that the sample contained about $20 \%$ more whites, and $10 \%$ fewer Hispanics than in the population. The sample also appeared to be more highly educated than the general population and was of slightly higher income.

\section{SURVEY ITEMS}

The dependent variable of political participation included the nine items listed in Table I. An index of political participation was constructed by counting the number of political behaviors reported by each respondent. An item analysis was performed to assess the reliability of this index and a Cronbach's alpha of 0.72 was obtained. The mean number of behaviors reported by respondents was 4.8 with a standard deviation of 1.9 .

A stress index was constructed by taking each individual's mean rating on four items. Respondents were asked how often they are worried or bothered about (1) money, (2) job, (3) family, and (4) their health. Response options included the following: never (coded 1), less than once a month, about once a month, about once a week, several times a week, every day, more than once a day (coded 7). An item analysis (Cronbach's alpha) yielded a reliability coefficient of 0.66 for this index. The mean on this seven-point index was 3.8 and the standard deviation was 1.3.

The independent variable of job autonomy was measured using five items from Vroom's (1960) measure (see Table II) and a sixth item for those who worked only at home. These items were combined to form an index of job autonomy by taking the mean score of the first five items for those who were employed, and by taking the last item for those who did not work outside the home. The mean job autonomy rating was 3.1 on a four-point index and the standard deviation was 0.7. Cronbach's alpha was used once again to estimate the reliability of the index and a reliability coefficient of 0.77 was obtained for the five-item index.

Contact by political organizations was assessed by asking respondents whether they had ever been contacted by a politician, a political group or party, by mail, telephone or in person (a separate question was asked for each mode of contact). The amount of contact by political organizations was then measured by an index counting the number of positive responses to the above three items. Scores ranged from 3.0 for no contact to 6.0 for all three modes of contact. A Cronbach reliability coefficient of .50 was obtained. The mean was 4.9 with a standard deviation of 0.9 .

Membership in social organizations was measured by asking the individual whether or not he/she belonged to any social organizations, and if so, how many. The mean number organizations was 1.2 with a standard deviation of 1.3 .

Locus of control was measured using five items from Rotter's (1973) scale. Three were political in nature and two were personal. Factor analysis indicated that these five items represented two separate factors with political items loading on one and personal items on the other. Together the two factors accounted for $62^{0} 10$ of the variance among the five items. A political locus of control index was constructed by taking the mean of the three political items. This index had a reliability of 0.64 , a mean of 1.6 (where external was coded 1.0 and internal was coded 2.0), with a standard deviation of 0.4. A 
personal locus of control index was constructed using the two personal items and yielded a reliability coefficient of 0.59 , a mean of 1.8 , and a standard deviation of 0.3 .

Income was measured by a question asking, "Does your total yearly family income fall into the: less than $\$ 10,000$ category?" (8\% of the sample); "the 10,000 to $\$ 15,000$ ?" (13\%); "\$15,000 to $\$ 20,000$ category?" (10\%), "20,000 to $\$ 30,000$ ?" (16\%); "\$30,000 to $\$ 40,000$ ?" (16\%); "\$40,000 to $\$ 50,000$ ?" (14\%); "\$50,000 to $\$ 60,000$ ?" (9\%); "\$60,000 to $\$ 70,000$ ?" ( $\left.5^{0} 70\right)$; "or over $\$ 70,000$ ?" $\left(6^{0} 70\right)$. Three percent of the respondents failed to answer the income question.

Education was measured in a similar way by asking, "Does your level of education fall into the less than high school category?" (4070); "Some high school?" (6\%); "High school graduate or GED?" (10\%); "Trade or vocational school?" (6\%); "Some college?" (2107o); "Associate degree?" (12\%); "B.A. or B.S.?" (18\%); "Advanced schooling or degree?" (21\%). Two percent of the respondents did not answer this question.

A rudimentary pretesting of the questionnaire was conducted by telephone and 15 randomly chosen respondents were interviewed. As a result of the pretest, several minor changes in item format and wording were made.

\section{Data Analysis}

Ordinary least squares regression analysis was performed on the data. All variables were standardized for the analysis since effect sizes may be biased by unequal variances (Cohen and Cohen, 1975). Age was entered into the regression first as a control variable because it was found to be significantly related to political participation and because the sample was somewhat older than the population. A stepwise procedure was then used to enter stress, job autonomy, contact by political organizations, membership in social organizations, political locus of control, and individual locus of control. It was thought that these variables might explain at least part of the relationship between SES and participation. Income and education were therefore entered into the equation on the final step to determine whether the other variables could reduce the effects of SES on political participation to nonsignificance.

Though Cohen and Cohen (1975) suggest that 0.6 may be considered an adequate reliability score for a public opinion survey, low reliability is a cause for concern in the present study. Unreliable measures bias estimates of effect sizes downward (Cohen and Cohen, 1975). Findings of the present study may generally be expected to underestimate the true strength of the relationships between variables.

\section{RESULTS}

Table III shows intercorrelations between independent variables and dependent variables. Results of the regression analysis predicting political participation are shown in Table IV. As indicated by the value of the adjusted multiple $\mathbf{R}$ square, $48 \%$ of the variance in political participation was accounted for in the analysis. The following variables explained a unique portion of the variance in the dependent variable (see Table IV): stress, job autonomy, contact by political organizations, number of social organizations belonged to, and income.

The fact that stress showed a significant final beta weight when the Pearson correlation was nonsignificant suggests the operation of a suppressor variable. An examination of partial correlations was undertaken to determine the nature of the suppressor effect. The partial correlation between participation and stress approached significance when job autonomy was controlled $(r=0.17, p<0.10)$. The partial correlation also approached significance when income was controlled $(r=0.17, p<0.10)$. No other partial correlations even approached significance. These results suggest that the suppressor 
effect was due to job autonomy and income. This fits in with the hypothesized relationship between stress, control, and job autonomy where it was suggested that control at work could reduce the effects of stress.

\section{DISCUSSION}

The present study was an attempt to develop explanations for varying levels of political participation. Several of the factors suggested as potential explanatory variables originated from Milgram's theory of overload (1970). The results from this study indicated that the amount of stress contributed significantly to the level of participation.

Other variables hypothesized to be important as a result of Milgram's hypothesis were among the most important predictors of all variables under study. In particular, contact by political organizations, which was theorized to reduce the stress involved in participation by providing specific information and activities, was found to have a significant impact on political participation. Other findings also indicated the importance of stress. For example, the most frequently cited reason for not working on a political campaign was simply being too busy $\left(50^{0} 70\right)$.

While the stress variable did significantly predict political participation, some limitations of the present study give us reason to suspect that the relationship between these two variables may be significantly stronger in the true population. One of these limitations is the self-selection bias inherent in almost all mail surveys. Persons with especially high levels of stress may not have returned questionnaires. Those pursuing similar research should survey by telephone those who do not return questionnaires after a second mailing. In addition, some way to verify self-reported participation is desirable since several researchers have noted the tendency for people to report that they have participated when in fact, they have not (Clausen, 1968; Katosh and Traugott, 1981; Volgy and Schwarz, 1984).

The reader should also be aware that the stress index has not been validated and may not adequately discriminate between persons of high and low stress. We were trying to develop a measure that would be both easy to use and would not constitute a questionnaire in and of itself. We had conceived of stress as the amount of worry about money, job, family, and health and requested that the respondent determine the frequency of worry. Upon reflection, we realize that this may be a difficult task, since worry is unlikely to be something that people monitor. For these reasons, the authors recommend that this line of research be pursued but that other measures of stress be examined. For example, Rahe and Arthur's (1978) Social Readjustment Scale (SRRS), a measure of the cumulative amount of stress to which an individual has been exposed over a period of time, may be a possible substitute. However, to fully examine differences in stress between high and low income persons the measurement of environmental stressors, such as overcrowding, the threat of victimization, etc., is also recommended.

We hypothesized that job autonomy would be positively related to political participation. Job autonomy did account for a significant portion

of the variance in political participation. Job autonomy was also found to reduce some of the effects of stress on political participation. This replicates the common finding that people who feel they have control over their lives are not as affected by stressors.

Contact by political organizations and membership in social organizations were the most important predictors of participation. These findings are consistent with earlier research in this area.

Income also accounted for a significant amount of the variance in political activity over and beyond that accounted for by other variables. Zipp et al. (1982) suggest that SES will still predict even after all these variables are partialled out because American political parties do not significantly address the concerns of lower income people. 
This research was intended to build on previous research on political participation. Though done with a small sample, the results confirm the findings of several studies using larger, more representative samples and while several measures had low reliability, $48^{\%} \%$ of the variance in political activity was accounted for. The present study adds to the previous work in this area in two ways. First, while most studies of political participation look only at voting behavior, the present study used a broad measure of political activity including campaigning, letter-writing, demonstrating, etc. Second, the present study adds to the existing literature the finding of a relationship between political participation and stress. Hopefully, our study will stimulate others to replicate our research with larger and more representative samples.

\section{REFERENCES}

Abramowitz, S. I. (1973). Internal-external control and social-political activism: A test of the dimensionality Rotter's internal-external scale. J. Consult. Clin. Psychol. 40: 196-201.

Acock, A. C., and Scott, W. J. (1980). A model for predicting behavior: The effect of attitude and social class on high and low visibility political participation. Social Psychol. Quart. 43: 59-72.

Almond, G., and Verba, S. (1963). The Civic Culture: Political Attitudes and Democracy in Five Nations, Little-Brown, Boston.

Armstrong, J. S. (1975). Monetary incentives in mail surveys. Public Opin. Quart. 39: 111-116. Clausen, A. (1968). Response validity: Vote report. Public Opin. Quart. 41: 51-64.

Cohen, J., and Cohen, P. (1975). Applied Multiple Regression/Correlation Analysis for the Behavioral Sciences, Lawrence Erlbaum, Hillsdale, N.J.

Dawson, R. E., Prewitt, K., and Dawson, K. S. (1977). Political Socialization, Little-Brown, Boston. Dillman, R. E., Prewitt, K., and Dawson, K. S. (1977). Political Socialization, Little-Brown, Boston.

Dillman, D. A. (1978). Mail and Telephone Surveys, Wiley, New York.

Elden, J. (1981). Political efficacy at work: The connection between more autonomous forms of workplace organization and a more participatory politics. Am. Polit. Sci. Rev. 75: 29-58. Erikson, R. S. (1981). Why do people vote? Because they are registered. Am. Polit. Quart. 9: 259-276.

Fendrich, J. M., and Tarleau, A. T. (1973). Marching to a different drummer: Occupational and political correlates of former student activists. Social Forces 52: 245-53. Gardell, B. (1977). Autonomy and participation at work. Human Relat. 30: 515-533.

Glass, D. C., Reim, B., and Singer, J. E. (1971). Behavioral consequences of adaptation to controllable and uncontrollable noise. J. Exp. Social Psycho!. 7: 244-257.

Gunn, W. J., and Rhodes, I. N. (1981). Physician response rate to a telephone survey: Effects of monetary incentive level. Public Opin. Quart. 45: 109-115.

Jackson, S. E. (1983). Participation in decision making as a strategy for reducing job-related strain. $J$. Appl. Psycho/. 68: 3-19.

Katosh, J. P., and Traugott, M. W. (1981). The consequences of validated and self-reported voting measures. Public Opin. Quart. 45: 519-535.

King, J. D. (1981). Comparing local and presidential elections. Am. Polit. Quart. 9: 277-290.

Kviz, F. J. (1984). Bias in a directory sample for a mail survey of rural households. Public Opin. Quart. 48: 801-806.

Lafferty, W. M. (1980). Sex and political participation: An exploratory analysis of the "female culture." Eur. J. Polit. Res. 8: 323-347.

Linsky, A. S. (1975). Stimulating responses to mailed questionnaires: A review. Public Opin. Quart. 39: 82-101.

McGlen, N. E. (1980). The impact of parenthood on political participation. West. Polit. Quart. 33: 297- 
313.

Milgram, S. (1970). The experience of living in cities. Science 167: 1461-1468.

Miller, P. L. (1982). The impact of organizational activity on black political participation. Social Sci. Quart. 62: 83-93.

Orbell, J. M. (1974). Protest and participation among southern negro college students. In Bowman, L., and Boynton, G. (eds.), Political Behavior and Public Opinion: Comparative Analyses, PrenticeHall, Englewood Cliffs, N.J.

Pateman, C. (1970). Participation and Democratic Theory, Cambridge University Press, Cambridge.

Powell, L. W., and Brown, C. W. (1981). Male and female differences in elite political participation:

Examination of the effects of socioeconomic and familial variables. West. Polit. Quart. 34: 31-45.

Quinn, R. P., and Shepard, L. (1974). The 1972-1973 Quality of Employment Survey, Survey Research Center, University of Michigan, Ann Arbor, Mich.

Rahe, R. H., and Arthur, R. J. (1978). Life change and illness studies: Past history and future directions. J. Human Stress' 4: 3-15.

Reimanis, G. (1982). Relationship of locus of control and anomie to political interests among American and Nigerian students. J. Social Psycho!. 116: 239-290.

Rotter, J. B. (1973). Internal vs. external control. In Robinson, J. P., and Shaver, P. (eds.), Measures of Social Psychological Attitudes, Institute for Social Research, Ann Arbor, Mich.

Sallach, D. L., Babchuk, N., and Booth, A. (1972). Social involvement and political activity: Another view. Social Sci. Quart. 52: 879-892.

Sanders, E. (1980). On the costs, utilities, and simple joys of voting. J. Politics 42: 854-863.

Scaturo, D. J., and Smalley, N. T. (1980). Locus of control as a multidimensional correlate of political involvement. J. Psychol. 105: 83-92.

Sherrod, D. R., Hage, J. N. Halpern, P. L., and Moore, B. S. (1977). Effects of personal causation and perceived control on responses to an aversive environment: The more control, the better. J. Exp. Social Psycho/. 13: 14-27.

Stone, W. F. (1974). The Psychology of Politics, The Free Press, New York.

Verba, S., and Nie, N. H. (1972). Participation in America: Political Democracy and Social Equality, Harper, New York.

Volgy, T. J., and Schwarz, J. E. (1984). Misreporting and vicarious political participation at the local level. Public Opin. Quart. 48: 757-765.

Vroom, V. (1960). Some Personality Determinants of the Effects of Participation, Prentice-Hall, Englewood Cliffs, N.J.

Wolfinger, R. E., Rosenstone, S. J., and McIntosh, R. A. (1981). Presidential and congressional voters compared. Am. Polit. Quart. 9: 245-256.

Zipp, J. F., Landerman, R., and Luebke, P. (1982). Political parties and political participation: A reexamination of the standard socioeconomic model. Social Forces 60: 1140-1153. 
Table I. Survey Items for the Political Participation Index

Are you registered to vote?

Did you vote in the 1980 Presidential election?

Did you vote in the 1982 Congressional election?

Do you intend to vote in this year's Presidential election?

Have you ever written or contacted your congressman?

Have you ever written or contacted any local or state officials regarding a problem or issue that concerned you?

Have you ever worked on a political campaign?

Have you ever been part of a political demonstration?

Have you ever acted on a political or social issue that concerned you?

Table II. Survey Items Used for Job Autonomy Index

(1) How much of a chance does your job give you to do the things that you are best at?

A lot. Some. A little. None.

(2) If you have a suggestion for improving the job or changing the set-up in some way, how likely is your supervisor to act on your suggestion?

Very likely. Somewhat likely. Somewhat unlikely. Very unlikely.

(3) In general, how much control do you have over how you perform your job, such as the pacing and ordering of tasks?

A lot. Some. A little. None.

(4) Does your immediate supervisor ask your opinion when a problem comes up that involves your work?

Always. Often. Sometimes. Rarely. Never.

(5) For you, how much is one working day just like the next? Not at all. Somewhat. A lot. Exactly the same.

(6) How much of a chance does working at home give you to use your skills and abilities?

A lot. Some. A little. None. 
Table III. Intercorrelations between Independent and Dependent Variables

\begin{tabular}{|c|c|c|c|c|c|c|c|c|c|}
\hline & (2) & (3) & (4) & (5) & (6) & (7) & (8) & (9) & (10) \\
\hline (1) & 0.11 & $0.33^{u}$ & $0.50^{a}$ & $0.48^{a}$ & $0.23^{a}$ & $0.10^{a}$ & $0.25^{a}$ & $0.24^{a}$ & $0.25^{a}$ \\
\hline (2) & & -0.10 & 0.00 & 0.13 & -0.09 & -0.11 & $-0.18^{h}$ & -0.02 & -0.05 \\
\hline (3) & & & $0.18^{b}$ & 0.12 & 0.16 & $0.18^{b}$ & 0.14 & 0.12 & 0.07 \\
\hline (4) & & & & $0.19^{b}$ & 0.09 & 0.08 & $0.21^{b}$ & 0.06 & $0.29^{a}$ \\
\hline (5) & & & & & $0.18^{b}$ & 0.03 & -0.07 & 0.11 & $0.29^{a}$ \\
\hline (6) & & & & & & $0.17^{*}$ & 0.09 & 0.14 & 0.04 \\
\hline (7) & & & & & & & 0.02 & 0.07 & -0.02 \\
\hline (8) & & & & & & & & $0.37^{a}$ & $-0.23^{a}$ \\
\hline (9) & & & & & & & & & $-0.24^{a}$ \\
\hline
\end{tabular}

Note. Numbers in parentheses represent the following variables: Participation (1), Stress (2), Job Autonomy (3), Contact by Political Organizations (4), Membership in Social Organizations (5), Political Locus of Control (6), Personal Locus of Control (7), Income (8), Education (9), Age (10).

${ }_{p}^{a}<<0.05$.

${ }^{b} p<0.01$. 
Table IV. Summary Table of Hierarchical Multiple Regression $^{a}$

\begin{tabular}{|c|c|c|}
\hline Variable & Pearson $r$ & Final Beta \\
\hline \multicolumn{3}{|l|}{$\begin{array}{l}\text { Step } 1 \\
\left(R^{2} \text { added } 0.06^{b}\right)\end{array}$} \\
\hline Age & $0.25^{b}$ & 0.12 \\
\hline \multicolumn{3}{|l|}{$\begin{array}{l}\text { Step 2: } \\
\left(\mathrm{R}^{2} \text { added } 0.41^{c}\right)\end{array}$} \\
\hline $\begin{array}{l}\text { Personal Locus } \\
\text { of Control }\end{array}$ & 0.10 & 0.02 \\
\hline Stress & 0.11 & $0.14^{d}$ \\
\hline $\begin{array}{l}\text { Political Locus } \\
\text { of Control }\end{array}$ & $0.23^{b}$ & 0.09 \\
\hline Job Autonomy & $0.33^{c}$ & $0.18^{b}$ \\
\hline $\begin{array}{l}\text { Contact by } \\
\text { Political } \\
\text { Organizations }\end{array}$ & $0.50^{c}$ & $0.32^{c}$ \\
\hline $\begin{array}{c}\text { Membership in } \\
\text { Social Groups }\end{array}$ & $0.48^{c}$ & $0.32^{c}$ \\
\hline \multicolumn{3}{|l|}{$\begin{array}{l}\text { Step 3: } \\
\left(\mathbf{R}^{2} \text { added } 0.05^{b}\right)\end{array}$} \\
\hline Education & $0.24^{b}$ & 0.12 \\
\hline Income & $0.25^{b}$ & $0.18^{d}$ \\
\hline \multicolumn{3}{|c|}{$\begin{array}{l}{ }_{a} n=126 ; \text { Multiple } \mathrm{R}^{2} \text { square }=0.51 ; \text { Adjusted multi } \\
\text { ple } \mathrm{R}^{2}=0.48 \\
{ }^{b} p<0.01 \\
{ }^{c} p<0.001 \\
{ }^{d} p<0.05\end{array}$} \\
\hline
\end{tabular}

